\title{
THE PHYSIOLOGICAL BASIS OF DORIAN GRAY'S PORTRAIT
}

\section{Giorgio Fanò-Illic ${ }^{1,3,4}$, Silvia Belia ${ }^{2}$, Giuliana Cocchia ${ }^{3}$, Vittore Verratti ${ }^{4}$}

\author{
${ }^{1}$ Agenzia Spaziale Italiana (ASI), U.O. Microgravità, Viale del Politecnico, Rome. \\ ${ }^{2}$ Dipartimento di Chimica, Biologia e Biotecnologie, Università di Perugia. \\ ${ }^{3}$ Centro Interuniversitario di Scienze dell'Uomo, Perugia. ${ }^{4}$ Dipartimento di Neuroscienze, Imaging e \\ Scienze Cliniche, Università “G. d'Annunzio", Chieti-Pescara
}

\begin{abstract}
Unfortunately or perhaps fortunately, aging is a natural process, associated with a gradual deterioration of biological and physiological systems (wear and tear) correlated to a chronic inflammation and oxidative stress that represent its specific hallmarks. This deterioration is the primary risk factor for major human pathologies, including cancer, diabetes, cardiovascular disorders, and neurodegenerative diseases.

There must be something both fascinating and intriguing about "old age" if, starting from the ancient greek and roman philosophers, poets and writers, up to our days' authors, so many have literary and poetically investigated and looked into a future from which you cannot escape, that is old age. The rhetorical figure of the best-known literary scene on the human immortal hope to reach the myth of the eternal youth, is certainly represented by Dorian Gray.

Today, the problem should be divided into two components: an "easier" one, linked to how you stay young, and a second (part) "a little '(sic) more complicated" one, referred to the processes that, by reversing the age-related mechanisms, allows the organs and tissues to recover the functional status of the age of twenty.

This review will try to answer with scientific data and a bit of irony to this dilemma.

Keywords: aging, immortality, rejuvenation.
\end{abstract}

The one charm about the past is that it is the past

(O. Wilde "The picture of the Dorian Gray")

\section{SENESCENCE AND DEATH:}

\section{THE SCIENTIFIC POINT OF VIEW}

The definition of aging is in itself open to various interpretations, although it may be shared the depiction of this process as the sum of all the physiological, genetic and molecular changes that occur as time goes, from fertilization of the oocyte to death. In the 18th century, Lamarck differentiated two kinds of death: accidental death (disease, predating and accidents) and natural death (aging), postulating that aging is due to intrinsic causes. This theory was compared to the "wear and tear" model: living bodies get weaker just as a knife's edge becomes dulled with use (1).

This means that the normal cellular activity itself is harmful to the body, and that this leads to its destruction, both directly and indirectly increased susceptibility to accidental death (2). The changes due to aging can be attributed to the natural process of growth, genetic defects linked to the individual, the relationship be-

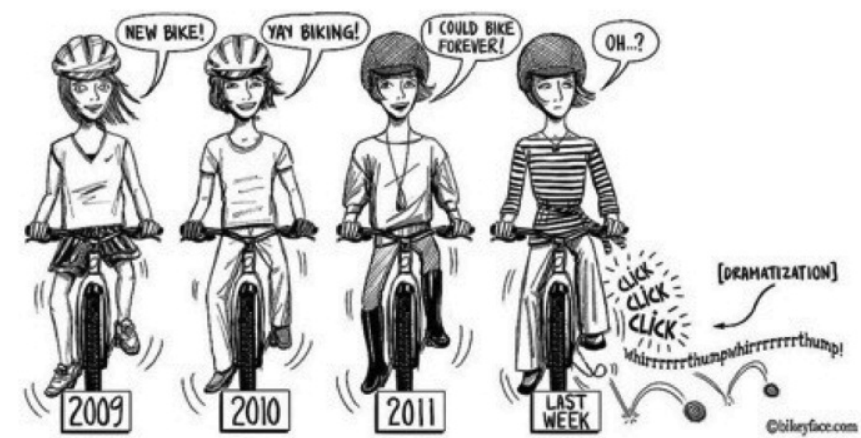

Figure 1. The metaphor of "Wear and tear" theory.

Correspondence to:

Giorgio Fanò-Illic

Dipartimento di Neuroscienze, Imaging e Scienze Cliniche, Università “G. d'Annunzio", Chieti-Pescara.

Tel. +39.0871.5413.99, +39.348.089.7627.

E-mail: fano@unich.it; fanoillic@gmail.com 
tween genotype and environment, the development of disease and aging, which in itself is the greatest risk factor for disease and death since the age of 28 in developed countries. Aging is therefore characterized by a set of changes that increases the risk of illness and death. A recent definition extends this concept even further by recognizing aging as a transformation that involves the body at any time, referring not only to changes associated with the loss (i.e. to senescence, which is the most commonly accepted definition for aging), but also the acquisition of functions (growth and development). Using this definition, the speed of aging would be synonymous of the speed of change. The rate of changing / aging is higher during the fetal period, when the organism develops from a single cell (at conception) to complex multicellular organism at birth. Therefore, the fetal aging would be determined by factors that regulate the speed of mitogenesis, differentiation and cell death and that are responsible for regulating aging throughout the life cycle (3).

Unfortunately or perhaps fortunately, aging is in a certain way a natural process, associated with a gradual deterioration of biological and physiological systems correlated to a chronic inflammation and oxidative

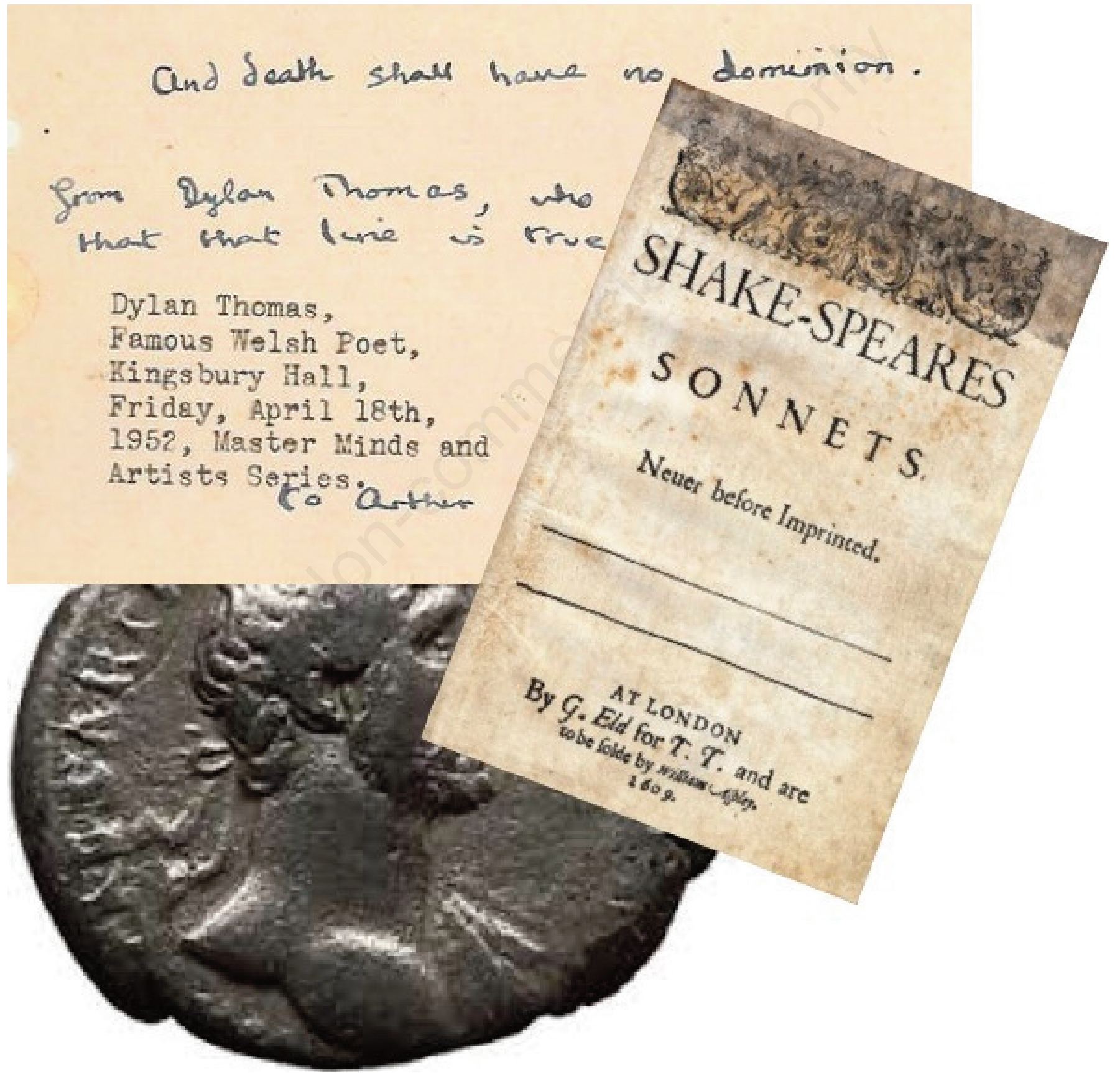

Figure 2. The path of senescence in poetry... 
stress that represent its specific hallmarks. This deterioration is the primary risk factor for major human pathologies, including cancer, diabetes, cardiovascular disorders, and neurodegenerative diseases. (4).

In conclusion, "Wear and tear" may certainly play a role in the process of aging. Enhanced metabolism of cells in various organs might result in enhanced cell damage, e.g. through the formation of free radicals, and consequently in a shortening of the life span. "The universality of this phenomenon suggests that the reactions it causes, are basically the same in every living things. Viewing this process in the light of present day, free radical and radiation chemistry of radiobiology, it seems possible that one factor in aging may be related to deleterious side attack taken by free radicals (which are normally produced in the course of cellular metabolism) on cell constituents"(5).

\section{SENESCENCE IN THE LITERARY HISTORY}

There must be something both fascinating and intriguing about "old age" if, starting from the ancient greek and roman philosophers, poets and writers, up to our days' authors, so many have literary and poetically investigated and looked into a future from which you cannot escape, that is old age.

Old age, "together with childhood, is the most profound status man has the chance to live", this is what Marguerite Yourcenar says, so why not consider a real privilege to entirely live this part of human life?

Of course Dylan Thomas in his "And death shall have no dominion"(6), expresses pure poetry and he captures our sensitiveness through his visionary modern way of making poetry...

When their bones are picked clean and the clean bones gone, They shall have stars at elbow and foot;

Though they go mad they shall be sane,

Though they sink through the sea they shall rise again;

Though lovers be lost love shall not;

And death shall have no dominion.

However, if we look back to ancient Greece, we will discover that the definition of old age and death is much different. Under this point of view, sentences like the following one can be read: "old age, dreary and sinister, old age like illness and enemy, old age like death" and this is the way history has looked at this stage of life, whose only merit is "sapientia", which merely derives from experience, as Cicero and Terenzio proclaim.

In more recent times (XVI/XVII century), Shakespeare (7) has no better opinion of old age and death if, writing about senility, he says....

That time of year thou mayst in me behold When yellow leaves, or none, or few, do hang Upon those boughs which shake against the cold,
Bare ruin'd choirs, where late the sweet birds sang. In me thou seest the twilight of such day ... (Sonnet 75)

It is still true that old age, senility is a time of sadness, when the body (and too often not only body) suffers from weakness, illness, deterioration.... and also the cognitive process changed. About this last issue, our italian singer and poet Francesco Guccini in his song "Il vecchio e il bambino" (the old man and the child) (8), says:

"I vecchi subiscon le ingiurie degli anni, non sanno distinguere il vero dai sogni, $i$ vecchi non sanno, nel loro pensiero, distinguer nei sogni il falso dal vero".

The old men suffer the ravages of time They cannot distinguish truth from dreams And in their thought They cannot distinguish false from truth While they dream (n.d.a.)

Shall we try to be a bit more optimistic and share the statement by $F$. Kafka?

"Youth is happiness because it has the capability of seeing beauty. Everyone who is able to maintain the ability of seeing beauty Shall never become old" (9).

\section{Old AGE: THE SOCIAL ASPECT}

... nine-tenths of the happiness derived from the state of health (Schopenhauer)

Old age is defined as the terminal period of life characterized by the gradual slowing of physiological functions and the decay of the body. Try to slow down aging and stay young you can then understand how to stay healthy.

Nowadays life expectancy has raised a lot, for example compared to 1800 and this is mainly due to the disappearance of many diseases and the availability of sufficient food (although in many parts of the world even today people are dying from malnutrition unfortunately).

Every second, there are two more people over sixty. In the report An Aging World : 2008, by Kevin Kinsella and Wan He, researchers at the U.S. Census Bureau, and commissioned by the National Institute on Aging (NIA) has been made an analysis of the aging of the global population, from which emerges a element that has no precedent in history: in less than ten years, for the first time, the number of people over 65 will exceed that of children under five (10).

In mid-2008, globally, people aged 65 years were, according to estimates, 506 million. From 2007 to 2008, the elderly population has grown, on average, in the 
world, with 870,000 people every month. In 1990, 26 countries had an aging population of at least two million people; in 2008, 38 countries have reached that threshold and in 2040 could be 72 . The research also points out that it is precisely the people aged 80 years or more to represent the portion of the population that is growing rapidly in many countries.

This represents a success, as it means better nutrition, improved hygiene, medical advances and advances in the field of education and hides in itself also a big plus, given the incredible productivity among the over-sixties. It is true, we live in a world increasingly older, but growing old with dignity and accompanied by appropriate services is the challenge to release to the future, the only battle that can be won, appropriate for everyone. The United Nations Fund for Population Activities (UNFPA) and the association HelpAge International, presented a report in which it was emphasized that the aging population is the real common thread that unites the countries of the planet, showing how the inevitability of this trend should be taken of the chest (?) for all levels and turning the challenge into an opportunity (11).

The aging population is not a bug in the more developed countries. In fact, according to the United World Population Division, in the world only Nigeria will not have an increase in the average age of the population over the next 10 years. So this is not a trend in the short or medium term, but a stable trend in which the marketing has to look carefully because new models will be needed to understand the needs of consumers. Ac-

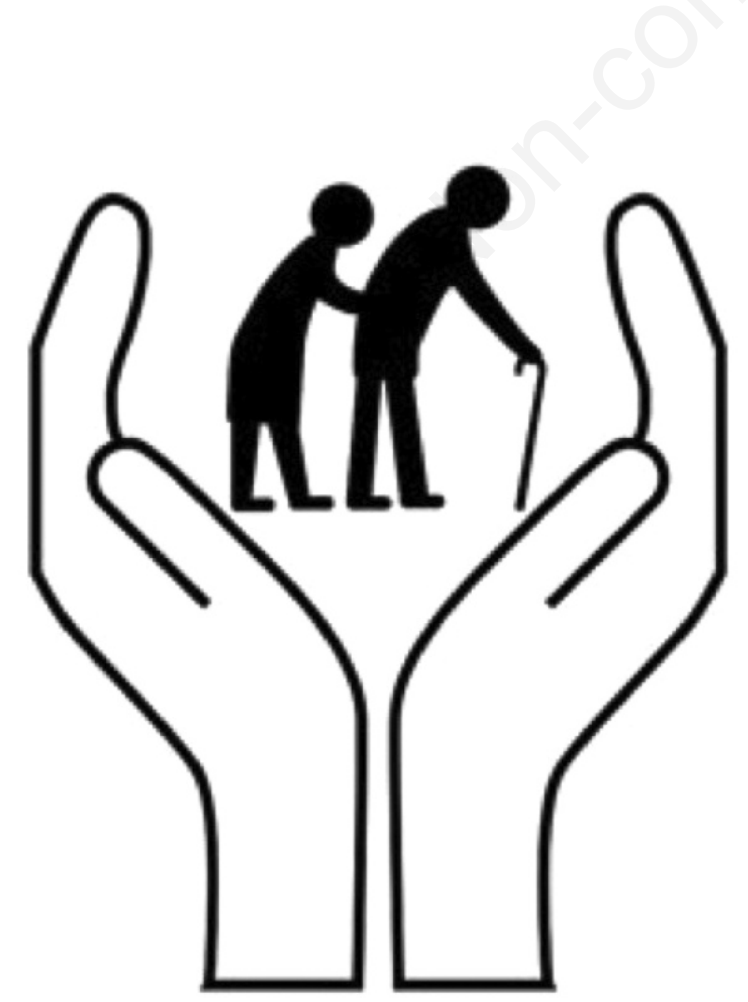

Figure 3. Old age is defined as the terminal period... cording to the United popolation Division, fertility rate is declining. At the global level it has dropped almost $48 \%$ from the ' 50 s to today and are expected to continue to decline by approximately $18 \%$ in the next 4 decades. The causes are many : the transition from an agrarian society to an industrial, urbanization and increase in the level of education, particularly that of women. In short, modern life does not coincide with a model of a large family and this has led to a social situation in which the increase of the older population is rapidly getting higher than the increase of the younger population.

\section{Senescence Versus Eternal Youth: the Molecular Biology}

The rhetorical figure of the best-known literary scene on the human immortal (or immoral?) hope to reach the myth of the eternal youth, is certainly represented by Dorian Gray, protagonist of the famous novel (The picture of Dorian Gray) that Oscar Wilde wrote in 1890 in which beauty becomes an insane rite. The story describes how a painter, Basil Hallward, fascinated by the beauty of the young Dorian Gray, his friend, paints his portrait. While all the young man's desires are satisfied, and first of all the desire never to grow old, mysteriously all the signs of life, pleasure, vice and fear deface the beautiful portrait, leaving Dorian's own face unmarked. Like Faust, in return for eternal youth he sells his soul (12).

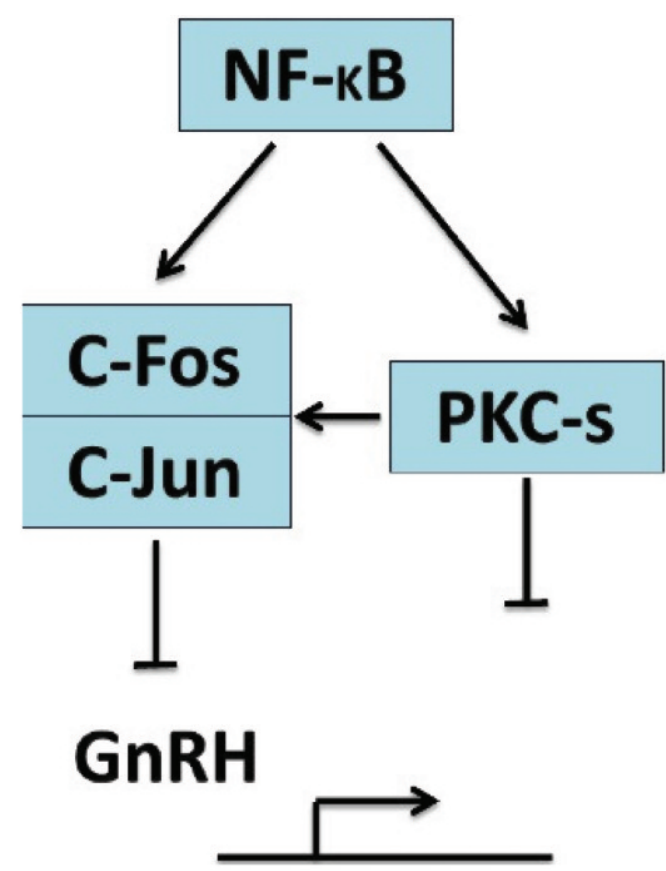

Figure 4. Schematic representation of GnRH inhibition by IKK $\beta / N F-K B$. 
Since the imagination of novelists, especially when describing man's dreams, often anticipates a truth that the progress rate makes explicit only later, we went to look, with great presumption and a hint of interest, at the scientific existence of such "hope".

Actually, the problem should be divided into two components: an "easier" one, linked to how you stay young, and a second (part) "a little '(sic) more complicated" one, referred to the processes that, by reversing the age-related mechanisms, allows the organs and tissues to recover the functional status of the age of twenty.

With regard to the "easy" aspect of the problem, over the past year some papers that have been immediately imposed to the expert's consideration, have appeared on some of the most famous scientific Journals,

The first of these concerns the extension, in animals of most evolutionary complexity, of scientific observations conducted on two experimental models widely disseminated in order to determine the life span or life expectancy, if you prefer, the worm C. elegans and the fruit fly Drosophila capable to influence, in a certain way, the environmental effect on genetic lifespan. Basically, directly or indirectly, in synergy with the insulin-like growth factors, some specific neurons are able to increase the lifespan blocking the degenerative processes and effectively opposing the wearing induced by the environment $(13,14)$. Similar mechanisms have been identified in the past year, even in mammals (mice), due to the research group coordinated by prof. Dongsheng Cai of the Albert Einstein College of Medicine, NY (USA) which found that the hypothalamus is a key factor for the progression of whole-body aging and involves hypothalamic immunity mediated by IKK $\beta / \mathrm{NF}-\kappa \mathrm{B}$ and related microglianeuron immune crosstalk. For the scientists of Cai's group, the main question is : can the hypothalamus play a key role in determining control and duration of senescence ? In addressing this question quite challenging, the authors started from the consideration that

\section{Phenotype of longevity}

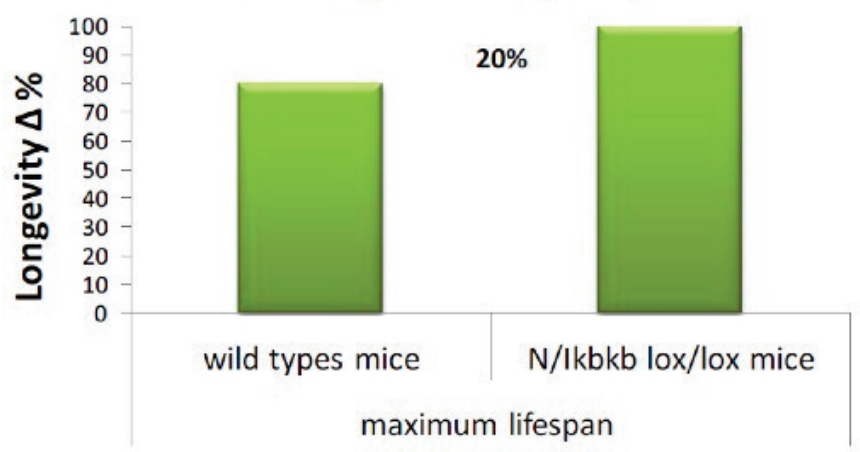

Figure 5. Genetic longevity in IKK $\beta$ knockout $(p<0.0002)$. modifications and/or inflammatory changes in the hypothalamus would regulate the development of different multifactorial syndromes such as obesity, metabolic syndrome, glucose intolerance, hypertension, etc. all disorders often present in the aging process. Increasing evidence now suggests that the brain and the immune system are closely connected and engaged in significant crosstalk to maintain homeostasis of the organism. In fact, immune cells and inflammation mediators in the CNS are usually linked both in normal and pathological states, while the neurons are able to interact with and regulate the immune cells (15). Recent data of Zhang et al. published in May 2013 (16), showed that the health general state and cognitive abilities of mice treated with molecules that block the NF-kB action via IKK $\beta$ inhibition, were improved. Also the maximum lifespan increased up to 20 percent under the same conditions. Studies on mechanism of action of this effect revealed that IKK $\beta / \mathrm{NF}-\kappa \mathrm{B}$ also inhibits hypothalamus GnRH production. GnRH is a gonadotrophin-releasing hormone: a peptide released from the hypothalamus capable to stimulate the pituitary gland to secrete gonadotrophic hormones whose production decreases proportionally with the age increasing.

Utilizing the words of prof. Cai it is possible to conclude: "in this work, we conceived that the hypothalamus, which is known to have fundamental roles in growth, development, reproduction and metabolism, is also responsible for systemic aging and thus lifespan control. Excitingly, through activating or inhibiting immune pathway IKK $/ N F-\kappa B$ in the hypothalamus of mice, we were able to accelerate or decelerate aging process, leading to shortened or increased lifespan. Thus, in line with the literature which appreciated the effects of the nervous system on lifespan, our findings provide a proof of principle to the hypothesis that aging is a life event that is programmed by the hypothalamus".

The hypothalamus was already known as a regulator of a number of neuroendocrine and autonomic functions. Now you will discover that it even induces aging. Two drug targets can slow down this action. They have exotic shapes: IKK $\beta$ and NF-kB but blocking them, the aging process slows.

The second "a little more complicated" component, is about to reverse the effects of genetic aging reporting the whole body or any of its individual component, to the glories of the now extinct past. Also for this problem, scientific research has shown during the past few months, a new molecular mechanism able to outline a new strategy to address the problem.

The main aspect of this point of view concerns the role played by mitochondria in the progression of the phenomena that affect aging cell. This organelle, maternally inherited as an ex parasite in the evolutionary history of life, contains an own genome capable of collaborating with the nuclear genome to ensure energy and stability to the cell. To determine this, a mitochon- 
drial mechanism plays a key role, that is represented by the oxidative phosphorylation, commonly known as OXPHOS, in managing the processes that involve the $\mathrm{O}_{2}$ availability and oxygen utilization and, consequently, the production of reactive oxygen species (ROS), key factors in determining the biological age of the cell.

Normally, the two genomes (nuclear and mitochondrial), cooperate in a synergistic way to the construction of the OXPHOS making it possible a correct synthesis of ATP. However, with the increasing of age, the system becomes unbalanced (mitochondrial deficiency) due to the decrease of nuclear factor $\mathrm{NAD}^{+}$, triggering a condition of pseudo hypoxia with consequent increase of HIF-1. The situation that is formed could be defined as a "genomic asynchrony" caused by a deficiency of the mitochondrial specific component(s). The mechanism that we have just described was discovered by the group of prof. David Sinclair of Harvard Medical School in Boston and published in Cell last December (17). The most interesting aspect of the work of Sinclair's group concerns the reversibility of the aging process. Because the problem is the availability of energy for cell functions, the Harvard scientists have focused their attention on skeletal muscle which has a high consumption (of it ?) for contraction necessity. In fact, in muscle tissue (that rapidly gets old through a specific process called sarcopenia), the Harvard's scientists have shown that if one can increase (by a phar-

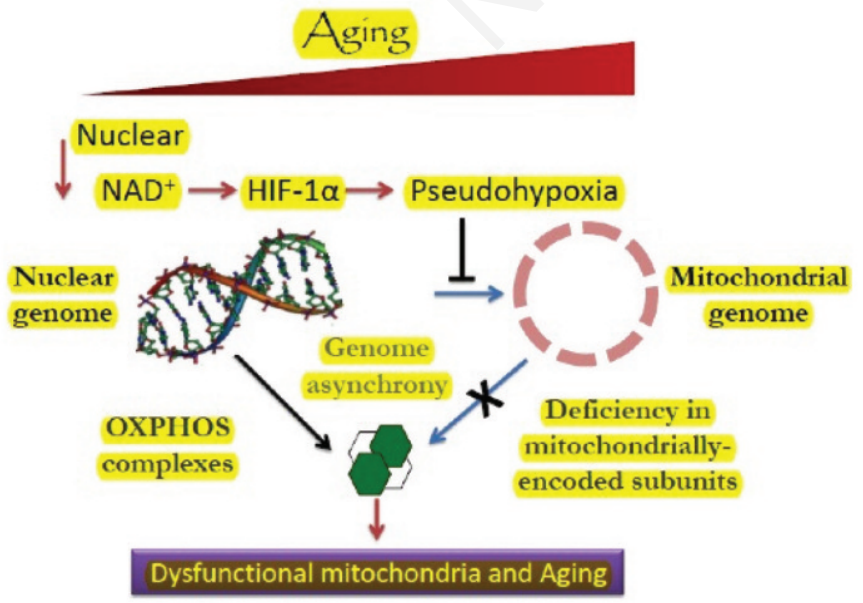

Figure 6. Mitochondrial dysfunction is a hallmark of senescence. During aging, there is a specific loss of mitochondrial, but not nuclear, encoded OXPHOS subunits. macological approach) the level of nuclear $\mathrm{NAD}^{+}$decreased with age, even sarcopenic status can be reversed. And so, in two year old mice, the increase of $\mathrm{NAD}^{+}$level has brought back the muscle tissue to 15 month mice! It 's like a 60 year old man returning to have the muscles of his 20 years.

Of course, applicative interest for the results obtained in the Harvard Medical School have indubitable and could be immediately finalized not just to regain the lost youth, but also for the treatment of some muscle diseases such as chronic fatigue syndrome (CFS) described as a disease in which "old muscles coexist in young bodies" (18).

\section{ANTI-AGING OR REGENERATIVE MEDICINE?}

In recent decades the anti aging therapies involving different areas of medicine, even if the term anti-aging is controversial and ambiguous, given that no single therapy has provided a longevity benefit in humans (19). In particular, the advancements achieved have boosted the progressive identification of age-associated epigenetic changes, amplifying the knowledge on the molecular basis of ageing and, as consequence of this, the mechanisms of age-related diseases. Also for this reason, today we try to provide a definition of antiaging medicine as a branch of medicine that can have as main goal the prevention, diagnosis, and treatment-

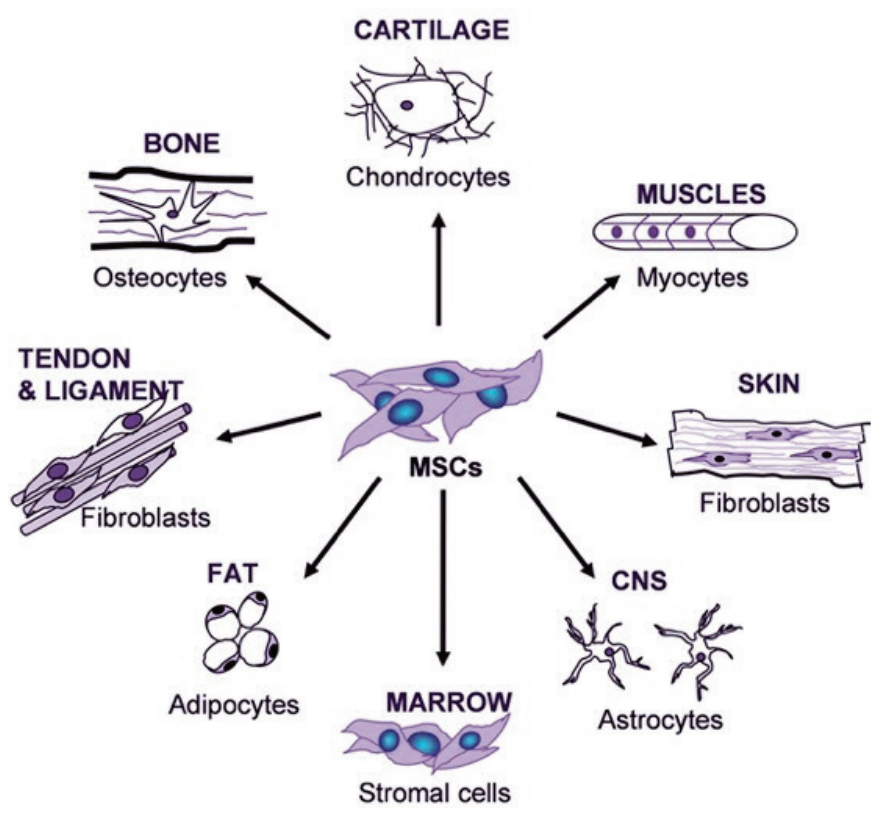

Figure 7. Regenerative capacity of mesenchymal stem cells. Europe currently leads the world in the therapeutic applications of stem cells. 
deceleration of the physiological processes associated with aging. If this is true, then the regenerative medicine bases its existence on research and treatments that restore damaged tissues $(20,21)$.

In conclusion, one can assert that the regenerative medicine and anti-aging medicine are two sides of the same medal who share a common path by developing new therapeutic treatments for intractable diseases and improving the quality of life.

Today, the promising aspects of regenerative medicine are: the stem cells that have been intensively studied for their potential applications in clinical medicine (22), the applications of genetic engineering and genomic (23) and, last but not least, the use of resources derived from nanotechnology (24).

However, exceed what is present in the literature, a clear profile of the anti-aging medicine can be delineated by a list of the topics that will be discussed in the next 12th Anti-Aging Medicine World Congress that you will do in Principality of Monaco in the next April 2014. As shown from the final program of this Congress, great interest is given to the classical surgery and aesthetic medicine. However, special attention is also assigned to regenerative therapies with stem cells show that have a huge potential role for the development of medical applications in the repair and regeneration of diseased organs and tissues, especially during old age (21). Regenerative medicine is one of the most promising fields of medical research, which offers the prospect of a reversal of the disease process. Europe currently leads the world in therapeutic applications of a number of technologies that fall under the heading of regenerative medicine. The first Europeandeveloped therapy based on human embryonic stem cell-based treatments for degenerative eye diseases, is due to enter the clinic in 2013.

Stem cells are naturally occurring cells in the body that have the ability to divide and produce a range of different cell types. Stem cells are important in the growth and development of the body, as well as in repair after injury. Despite their promise, however, there is uncertainty over the possible drawbacks of using stem cells in medicines. These include unpredictable and potentially serious risks such as the development of tumors and rejection by the body (25).

Even if some EU member states and pro-life members of the European Parliament are lobbying for the existing restrictive rules on funding embryonic stem cell research, the Horizon 2020 program provides a strong funding. The European Commission's approach to funding regenerative medicine research in Horizon 2020 is based on the assessment that it is potentially a high value technology that will deliver life-changing treatments.

\section{Conclusions}

Today, is it conceivable to think that you can escape from getting old or, in alternative, to decline very slowly? Some think that natural-pharmacological remedies are an attempt to delay aging (or to make it more attractive). I will mention only some of the most well known ones: gerovital, melatonin, ginkgo biloba, ginseng, papaya, atlantic sponges, jellyfish, GH, DHEA, vitamins, supplements, antioxidants... and so on.

However, it is clear that the "mare magnum" of information is not supported by scientific basis, since there aren't any, but, more simply, by mere market rules that means the usual unhealthy attitude to generate profit. In this "mare magnum" illusionists and charlatans who promise wellness are dramatically increasing, but fortunately, beside those, there are many qualified professionals operating in this field with appropriateness of resources and knowledge and with reassuring ethic profiles.

However, the only certain result that the use of such approaches has reached, has been to increase the turnover of the commercial system that revolves around the "Dorian Gray" effect. The sales of antiaging, comes to $\$ 50$ billion in 2006 and over 70 billion in 2009. Today has touched \$ 100 billion. Money are spent on products of limited effectiveness if not redundant and that, in addition, sometimes have series of contraindications for the health of the users. With the aging the joints become stiffer, the height is reduced, the hair turns white, the skin becomes wrinkled and less elastic, the muscles are reduced and the force of contraction decreases, you become presbyopic, blood pressure increases and the arteries become stiffer and you could go on and on. It is obvious that you cannot stay young forever, but the physical or psychological deterioration could be delayed and minimized by taking care of one's own life and with the greatest self respect.

Some simple rules applicable to a more natural lifestyle can be summarized in three main points provided that the economic resources available are sufficient:

\section{MOVE, MOVE, MOVE}

2. HEALTHY EATING... not a little or a lot, but good!

3. LOVE... that does not mean only to love.

But if, instead, a little bit of arthritis or back pain prevent you from moving as you would like to and the increase in body weight would only aggravate the situation by significantly limiting the desire to love, then... let's LAUGH and let LAUGHING be our refuge.

Physiological changes made by a number of laughs are comparable to those found as a result of aerobic activity without the side "unwanted" effects that this activity often acts like muscle tension, muscle pain, inflammation, etc...

The most obvious benefits of laughter are: 
- Increase in oxygenation of the blood;

- Replacement of the reserve air in the lungs;

- Stimulation of serotonin production;

- Stimulation of endorphin release;

- Stimulation of antibody production;

- Increase of blood circulation organs;

- The improvement of abdominal muscle tone;

- ... and much more.

In synthesis, you can continue to consider yourself young, if you are still able to laugh and smile looking at your wrinkles, considering them just as signs of life, to say it with Mark Twain (26):

"Wrinkles should merely indicate where the smiles have been."

\section{REFERENCES}

1. Walker RF. Is aging a disease? A review of the Serono symposia workshop held under the auspices of the 3rd World Congress on the aging male. February 9, 2002, Berlin, Germany 2002. Vol. 5, No. 3. $p p$ 147-169.

2. Dufour E, Larsson NG. Understanding aging: revealing order out of chaos. Biochim Biophys Acta 2004;1658:122-32.

3. Atwood CS, Bowen RL. The reproductive-cell cycle theory of aging: an update. Exp Gerontol 2011;46:100-7.

4. López-Otín C, Blasco MA, Partridge L, et al. The hallmarks of aging. Cell 2013;153:1194-217.

5. Harman D. The aging process. Proc Natl Acad Sci USA 1981;78:7124-8.

6. Ferris P. Dylan Thomas, a biography. New York: Paragon House; 1989.

7. Shakespeares W. Shake-Speares Sonnets. Published by Thomas Thorpe (TT) in 1609 and printed by G. Eld.

8. F.Guccini - Radici (Label:Columbia - 3C 064-17825) Vinyl, LP, Album, 1972, Italy

9. Kafka F. Die Verwandlung. In: Die Weißen Blätter. Eine Monatsschrift. (The White Pages. A Monthly). ed. René Schickele. "Jg. 2" (1915), "H. 10" (October), ps. 1177-1230.
10. Kinsella K, Wan H. US. Census Bureau. International Population Reports,. P95/09-1, An Aging World: 2008,. U.S. Government Printing Office

11. HelpAge International. Available from: http://www.helpage.org/

12. Wilde $O$. The picture of Dorian Gray. Lippincott's Monthly Magazine, 1890

13. Wolkow CA, Kimura KD, Lee MS, Ruvkun G. Regulation of C. elegans life-span by insulinlike signaling in the nervous system. Science 2000;290:147-50.

14. Alcedo J, Kenyon C. Regulation of C. elegans longevity by specific gustatory and olfactory neurons. Neuron 2004;41:45-55.

15. Lucin KM, Wyss-Coray T. Immune activation in brain aging and neurodegeneration: too much or too little? Neuron 2009; 64:110-22.

16. Zhang G, Li J, Purkayastha S, et al. Hypothalamic programming of systemic aging involving IKK $\beta / N F-\kappa B$ and GnRH. Nature 2013;497:211-6.

17. Gomes AP, Price NL, Ling AJ, et al. Declining NAD+ induces a pseudohypoxic state disrupting nuclear-mitochondrial communication during aging. Cell 2013;155:1624-38.

18. Fulle $S$, Pietrangelo T, Mancinelli $R$, et al. Specific correlations between muscle oxidative stress and chronic fatigue syndrome: a working hypothesis. J. Musc Res Cell Motil 2007;28:355-62.

19. Kamel NS, Gammack J, Cepeda O, Flaherty JH. Antioxidants and hormones as antiaging therapies: high hopes, disappointing results. Cleve Clin J Med 2006;73:1049-58.

20. Everts Mykytyn C. A history of the future: the emergence of contemporary anti-ageing medicine. Sociol Health Illn 2010;32:181-96.

21. Daughtry B, Mitalipov S. Concise review: parthenote stem cells for regenerative medicine: genetic, epigenetic, and developmental features. Stem Cells Transl Med. 2014 Jan 17 [In Press].

22. Preethy S, John S, Ganesh JS, et al. Age-old wisdom concerning cell-based therapies with added knowledge in the stem cell era: our perspectives. Stem Cells Clon 2013;6:13-8.

23. Horch RE, Kneser U, Polykandriotis E, et al. Tissue engineering and regenerative medicine -where do we stand? J Cell Mol Med 2012;16:1157-65.

24. Farina M, Ye T, Lanzani $G$, et al. Fast ultrahigh-density writing of low-conductivity patterns on semiconducting polymers. Nature Commun 2013;4:2668.

25. European Medicines Agency, Committee for Advanced Therapies (CAT). Reflection paper on stem cell-based medicinal products. Available from: http://www.ema.europa.eu/docs/en_GB/document_library/Scientific_guideline/2011/02/WC500101692.pdf

26. Cox JM. Mark Twain: the fate of humor. Princeton: Princeton University Press; 1966. 